\title{
Internet gamblers: a latent class analysis of their behaviours and health experiences.
}

\author{
Joanne Lloyd-White, Helen Doll, Keith Hawton, William H Dutton, John \\ R Geddes, Guy M Goodwin \& Robert D Rogers
}

Oxford University Department of Psychiatry (JL, KH, JRG, GMG \& RDR); Oxford University Department of Public Health (HD); Oxford Internet Institute (WHD).

\section{Final submitted version of:}

Lloyd, J., Doll, H., Hawton, K., Dutton, W. H., Geddes, J. R., Goodwin, G. M., \& Rogers, R. D. (2010). Internet gamblers: A latent class analysis of their behaviours and health experiences. Journal of Gambling Studies, 26(3), 387-399.

Acknowledgements: This research was supported by a grant from the Economic and Social Research Council (ESRC) and the Responsibility in Gambling Trust (RIGT). Funding bodies had no influence over design and conduct of the study; collection, management, analysis, and interpretation of the data; and preparation, review, or approval of the manuscript. We thank the Remote Gaming Association (RGA); the European Gaming and Betting Association (EGBA); Dr. Ellen Helsper; Sue Simpkin; and Rebecca Chandler for their invaluable assistance throughout the project. 


\section{ABSTRACT}

In order to learn about the behaviours and health experiences of people who gamble on the Internet, we conducted an International online survey with a self-selecting sample of web users, recruited via hyperlinks on gambling and related websites. The mean (SD) age of the 4,125 respondents who completed the survey was 35.5 (11.8) years, with $79.1 \%(3,263)$ being male. $68.8 \%(2,838)$ were UK residents. Respondents provided demographic details and self-report information on their use of online gambling services, and completed validated psychometric screening instruments for problem gambling, mood and substance misuse disorders, and history of deliberate self harm. A latent class analysis segmented respondents into 5 clusters $\left(\mathrm{L}^{2}=44.27\right.$, bootstrap $p=0.07$ ) based on their patterns of regular online gambling activities, with clusters named according to their characteristic activity profiles as 'non-to-minimal gamblers'; 'sports bettors'; 'casino \& sports gamblers'; 'lottery players'; and 'multiactivity gamblers'. There were significant inter-cluster differences in the proportion of individuals scoring above threshold for problem gambling and in the prevalence of mood and substance misuse disorders, and history of deliberate self harm (all $X^{2} s>23.4$, all p-values $\left.<0.001\right)$. The 'casino \& sports' and 'multi-activity-gamblers' clusters had the highest prevalence of mental disorder. Internet gamblers appear to be heterogeneous but composed of several clear subtypes, differing markedly on both their demographic and clinical characteristics. These findings can inform the development of appropriate interventions for problematic gambling on the Internet.

\section{Keywords:- Gambling; Internet; Gambling activities; Mood disorders}




\section{INTRODUCTION}

Internet gambling has grown substantially during the last decade, raising concerns that the increased opportunities for gambling online represent a significant public health issue and spurring regulatory interventions within Europe, the United States and other jurisdictions (Clarke and Dempsey 2001). Despite widespread speculation about potential negative consequences of Internet gambling (Griffiths et al. 2006; Griffiths and Barnes 2007; Ladd and Petry 2002; Petry and Weinstock 2007; Wood and Williams 2009), little is known about the way that people use online gambling services or the health experiences of Internet gamblers. A few, mostly small scale, studies have suggested that Internet gamblers are at increased risk of problem gambling (Griffiths et al. 2009; Griffiths and Barnes 2007; Ladd and Petry 2002; McBride and Derevensky 2009; Wood et al. 2007), alongside alcohol and drug misuse and poorer mental health (Petry and Weinstock 2007) while a recent US survey of almost 2,000 Internet gamblers found that over $40 \%$ of respondents met criteria for problem gambling (Wood and Williams 2007). By contrast, analysis of betting patterns has demonstrated seemingly well-controlled, moderate gambling behaviour in the vast majority of both sports bettors (LaBrie et al. 2007) and casino-game players (LaBrie et al. 2008) in a sample of over 40,000 account holders with a large European sports betting service. Thus, drawing reliable inferences about the health-related effects of Internet gambling is difficult. A recent general population survey showed that Internet gambling is still a relatively low prevalence phenomenon (Wardle et al. 2007), making it hard to build an accurate picture of the characteristics of Internet gamblers and their health. About 3\% of the general populations in the United States and Western Europe meet criteria for problem gambling, around 1/3 of whom also meet criteria for the more severe 'pathological' gambling' (Stucki and Rihs-Middel 
2007). These disorders are associated with substantial emotional and financial distress for gamblers and their families (Shaw et al. 2007), and measurable societal costs (Ladouceur et al. 1994). Furthermore, the functional consequences are worsened by the high comorbidity of problem gambling with other mental disorders, including unipolar depression and bipolar disorder (McIntyre et al. 2007), alcohol dependence and substance abuse (Kessler et al. 2008), as well as increased suicide ideation and attempts that are most frequently attributed to mood related, comorbid illnesses (Hodgins et al. 2006). This comorbidity reduces identification of problem gambling in the clinic and the efficacy of available therapies (Petry et al. 2005). In fact, researchers have called attention to the need for improved awareness of problem gambling in the medical and health professions (Griffiths 2004), while a recent report provided by the British Medical Association to the UK National Health Service recommended that screens for problem gambling should be employed as a matter of course in drug and alcohol treatment services and other mental health facilities (British Medical Association 2007). Considering the clinical impact of problem gambling and its associated comorbidity, together with the relative anonymity (and potential social isolation) of the Internet, it is important to learn more about the health experiences of people who gamble online. This information will facilitate the development of assessments and interventions for individuals who experience problems controlling their online gambling. Different forms of gambling can be associated with degrees of gambling involvement through a variety of social and psychological mechanisms (LaPlante et al. 2009; Petry 2003; Welte et al. 2007), and the likelihood of successful recovery may vary according to gambling preferences. For example, a recent largescale survey suggests that gambling problems involving casinos are associated with relatively higher odds of recovery, while problems involving slot machines, bingo and 
instant-win cards are associated with lower odds of recovery (Kessler et al. 2008; Petry 2003). Such differences may reflect distinct structural characteristics of gambling activities (Griffiths 1993), and/or personality factors (Nower et al. 2004) that predispose to mental disorder and may contribute to the complex phenotype of problem gambling. Here, we surveyed a large, self-selecting sample of people who gamble using the Internet, with the objective of eliciting descriptive data on different combinations of Internet gamblers' online gambling behaviours and associated health experiences.

\section{METHOD}

The survey was joint funded by the Economic and Social Research Council (RES164-250008) and the Responsibility in Gambling Trust, and approved by a National Health Service Research Ethics Committee (OXREC C; 06/Q1606/151). A selfselected sample of Internet users were recruited between July and November 2007, via hyperlinks placed with a number of gambling and gambling-related websites registered within Europe. Full details of the questionnaire are presented in the Supplementary Material. Bias towards Internet users was not problematic from the point of view of study design, as this group formed our target population. Upon entering the survey website, potential respondents were presented with a detailed information sheet and gave informed consent by clicking a 'radio' button to confirm that they had read this information and agreed to participate. Respondents provided information about their online gambling behaviour (i.e. frequencies, preferred activities, modes of access), and completed a number of validated screening questionnaires for psychological disorders. These included the 10-item criteria for DSM-IV problem gambling (American Psychiatric Association 2000), General Health 
Questionnaire (GHQ-12) (Goldberg et al. 1997), Patient Health Questionnaire PHQ-9 (Spitzer et al. 1994) to screen for possible depression and panic disorder, Mood Disturbance Questionnaire (MDQ) (Hirschfeld et al. 2000) to screen for previous mood elevation and symptoms of bipolar disorder, CAGE alcohol screen (Ewing 1984), and the 10-item Drug Abuse Screening Test (DAST) (Skinner 1982).

Respondents provided information about previous deliberate self harm (DSH; intentional self poisoning or self injury), past-year prescription medications, and pastyear illicit substances used, as well as parental gambling. In addition to demographic items, other questions elicited information about motivations for gambling online and their use of the Internet beyond gambling services (these data are not reported here).

\section{DATA ANALYSIS}

The demographic characteristics and proportion of the sample reporting different types of online gambling activities and mood and substance use disorders were described using statistics such as N, \%, and modal frequency. Latent class analysis (LCA), using Latent Gold 4.0 (Vermunt and Magidson 2003), was applied to the online gambling activities to identify subgroups of respondents to identify particular patterns of gambling behaviour. LCA solutions with varying numbers of classes were fitted to detect, among all significant models, the most parsimonious model with the best $\mathrm{L}^{2}$ value and which had a nonsignificant $\chi^{2}$ statistic with $\mathrm{P}<0.05$ (using the bootstrap $\mathrm{L}^{2}$ value), small bivariate residuals, and which remained stable when tested across multiple runs (see Supplementary Material for details of the LCA and the most robust model construction). Once we had identified subgroups of individuals with different gambling patterns, behavioural and clinical characteristics were compared using nonparametric statistics; $\chi^{2}$ tests were used to compare subgroups in terms of 
frequency data such as DSM-IV 'caseness'. Where the $\chi^{2}$ tests revealed significant differences, post-hoc partitioning of the $\chi^{2}$ statistic (Siegel 1956) was used to test where significant differences lay. Significance throughout was taken at $\mathrm{p}<0.05$.

\section{RESULTS}

There were 7,891 respondents who started the survey, of whom 4,125 completed. Of the 4,125 surveys completed, missing data were present in just $1.1 \%$ of cases, because respondents were required to complete all items. Results reported here are based upon completed surveys only. The sample characteristics are summarised in Table 1.

A 5-class LCA solution provided the most parsimonious and stable model with the best $\mathrm{L}^{2}$ value $\left(\mathrm{L}^{2}=44.27\right.$, bootstrap $\left.\mathrm{p}=0.07\right)$ and with no bivariate residuals above 2.84. Figure 1 shows the 5-class solution as the probability of participating in each gambling activity (or activity group) for each cluster. The clusters included: (i) individuals who played little (at most 1 online gambling activity, usually poker) $(36.6 \% ; n=1,619)$; (ii) individuals whose gambling was broadly confined to sports betting (with online bookmakers or betting exchanges) $(34.7 \% ; n=1,418)$; (iii) individuals who took part in sports betting and casino gambling (meaning 1 or more of casino games, slots, bingo or poker) $(15 \% ; \mathrm{n}=614)$; (iv) individuals whose online gambling was confined to lottery play $(9.3 \% ; n=379)$; and $(v)$ a very small number of individuals who played all 6 forms of gambling $(1.5 \% ; n=60)$. Table 1 shows the number and percentage of respondents in each cluster, and demographic characteristics. Clusters 2 and 3 (mainly sports bettors) were overwhelmingly male. Cluster 4 (lottery players) was almost equally male and female, and the multi-activity cluster was intermediate (Table 1) (see Supplementary Material for more details). 
INSERT FIGURE 1 ABOUT HERE:

INSERT TABLE 1 ABOUT HERE:

\section{HEALTH EXPERIENCES}

Table 2 shows that different combinations of online gambling activity, as identified by the five LCA clusters, were associated with differences in problematic gambling, depressive symptoms, previous mood elevation, deliberate self harm (gamblingrelated and nongambling-related), substance misuse, and alcohol use (all $X^{2} s>23.4$, ps<0.001).

Problem gambling. Post-hoc partitioning of the $\chi^{2}$ statistics revealed that the multiactivity cluster had a higher prevalence of problem gambling than any other cluster (ps $<0.05$ ), and that the casino \& sports bettor cluster had a higher prevalence than the sports bettor cluster $(\mathrm{p}<0.05)$. The prevalence of problem gambling was not significantly higher in the lottery players cluster compared to the non-to-minimal gambler cluster but was significantly lower than the other clusters (ps<0.05).

The percentage of respondents who reported having parents who gambled varied significantly across LCA clusters $\left(\chi^{2}=68.8, n=4, p<0.001\right)$, as did the percentage of respondents who reported that their parents had gambling problems of their own $\left(X^{2}=36.3, \mathrm{df}=4\right.$, exact $\left.\mathrm{p}=0.001\right)$. The 'casino \& sports' cluster and the 'multiactivity' cluster were significantly more likely than the other clusters to report parental gambling and parental problematic gambling behaviour $(\mathrm{ps}<0.05)$. 
Mood disturbance. Significantly more casino \& sports gamblers reported hypomanic experiences and mood disturbance than the sports bettor, lottery players, and non-tominimal gamblers clusters $(\mathrm{ps}<0.01)$. The multi-activity cluster also contained significantly more mood-elevation cases than any other cluster (ps $<0.05)$.

\section{INSERT TABLE 2 ABOUT HERE}

Depression and panic. The multi-activity cluster had a higher prevalence of depressive cases than any other cluster of respondents $(\mathrm{ps}<0.05)$; there were more depressed cases amongst casino \& sports gamblers than amongst non-to-minimal gamblers; lottery and non-to-minimal gambler clusters did not differ from one another. Interestingly, the sports bettors cluster contained significantly fewer cases of both depression $(\mathrm{ps}<0.01)$ and panic disorder $(\mathrm{ps}<0.05)$ compared to all other clusters.

Deliberate self-harm (DSH). The casino \& sports cluster reported more gamblingrelated deliberate self-harm (DSH) than both the non-to-minimal and lottery players clusters (ps<0.05). Gambling-related DSH was also more frequent amongst female members of the sports bettor cluster than female members of the non-to-minimal cluster ( $\mathrm{ps}<0.05$ ). By contrast, the sports-bettor, and the casino \& sports bettor clusters, reported significantly less non-gambling-related DSH than the non-tominimal cluster $(\mathrm{ps}<0.05)$. Non-gambling-related DSH was also less frequent in the sports bettor cluster compared with the lottery players cluster (ps $<0.05)$. The multiactivity cluster reported significantly more gambling-related DSH and non-gamblingrelated DSH compared to any other cluster of respondents in our survey $(\mathrm{ps}<0.01)$. 
Prescription medication. The use of prescription antidepressants within the last 12 months also differed across the five clusters of gamblers $\left(\chi^{2}(4, \mathrm{~N}=4079)=113.29\right.$, $\mathrm{p}<0.001)$. With the exception of the non-to-minimal and the casino \& sports clusters, which were not significantly different from one another, all between-cluster differences were statistically significant (see Table 3). Most notably, past year antidepressant use was significantly reduced in the sports bettor and the casino \& sports clusters, compared with each of the other clusters $(\mathrm{ps}<0.01)$.

INSERT TABLE 3 ABOUT HERE

Substance and alcohol use. There were significant differences in past year use of illicit substances: $X^{2}(4, \mathrm{~N}=4079-4084)>49.5, \mathrm{p}<0.001$ (Table 3), with more past year users of every listed substance (marijuana, amphetamines, cocaine, ecstasy, heroin, benzodiazepines and nicotine) being found in the multi-activity cluster than any other (ps<0.05). The casino \& sports cluster contained more users of each substance compared with the non-to-minimal and the sports bettor clusters (all ps $<0.05$ ). Cases of probable substance abuse (as identified by the DAST) were also significantly increased in the casino \& sports cluster and the multi-activity cluster compared with all other clusters (ps<0.05), and significantly more cases were observed in the multiactivity cluster than in the casino \& sports cluster $(\mathrm{p}<0.05)$ (see Table 2$)$. Analysis of alcohol misuse (as identified using the CAGE) showed a similar number of cases in the casino \& sports cluster compared to sports bettor cluster, but significantly more than in both the non-to-minimal and lottery players cluster $(\mathrm{ps}<0.01)$. Again, the multiactivity cluster contained a significantly higher proportion of above-threshold CAGE cases than any other cluster $(\mathrm{ps}<0.05)$ (see Table 2$)$. Finally, the number of 
people reporting that they had previously sought help for an addiction also varied by gambling activity, $X^{2}(4, \mathrm{~N}=4079)=14.35$, exact $\left.\mathrm{p}=0.007\right)$; specifically, the casino \& sports cluster reported significantly more treatment requests than any other cluster except for the multi activity cluster $(\mathrm{ps}<0.05)$.

\section{DISCUSSION}

We have found that groups of individuals with different patterns of Internet gambling activity can be identified empirically, and that these groups differ markedly in their risk of psychological morbidity. The most affected two groups participated in multiple and various online gambling activities including casino \& sports betting, and together, provided $16.5 \%$ of our sample. These individuals were more likely to have gambling problems, and also more likely to report specific difficulties including previous experiences of mood elevation, alcohol and substance misuse. They were also more likely to have engaged in self-harm as a consequence of gambling involvement. However, by contrast, the majority of our survey respondents used the Internet for single gambling activities such as sports betting, poker, or scratch cards/lottery play. In general, these more circumscribed forms of Internet gambling showed weaker associations with psychological morbidity in a way that is comparable to previous investigations of land-based gambling (LaPlante et al. 2009). A major strength of our study is the emergence of significant differences between apparently distinct groups of individuals who use Internet gambling services in varied ways. This in itself provides some validation of our latent class analysis model, implying that the clusters we have identified reflect true divisions. Our exploration of how different patterns of gambling activities are associated with divergent demographic characteristics, psychological risk factors, and health experiences may thus be helpful for informing regulatory 
policy, and in the development of interventions for individuals whose Internet gambling might become problematic.

\section{Limitations}

Any survey of this kind has inherent limitations (see Supplementary Materials for further discussion). These are best acknowledged a priori. While we are unable to physically monitor respondents or assess their truthfulness, this problem is common to other methods such as postal surveys, and it is thought that, on balance, online surveys can generate valid and reliable response sets (Wood and Griffiths 2007b). As in any survey, we have to trust the information provided by respondents, and our main protection from idiosyncratic responding lies in the large number of completers, although the possibility of a bias in type of respondents who would self-select for such a survey cannot be ruled out, nor can a bias in the type of respondents completing the survey, rather than dropping out part way through. Previous largescale prevalence surveys on Internet use, including gambling behaviour, have found that questions about marital status, residence and income can be experienced as intrusive, discouraging respondents from completing the rest of the survey (http://www .oii.ox.ac.uk/microsites/oxis/). To counter this possibility and in order to maximise the likelihood that respondents would complete our questionnaire, we located the demographics section of our survey at the end of the survey. As a consequence, we are unable to say much about the demographic features and gambling behaviour of respondents who did not complete the survey. Also, our data, being correlational in nature, cannot illuminate the precise nature of relationship between patterns of online gambling activity on the one hand, and mood and substance use problems on the other; so an important question for future research 
concerns the temporal relationship and direction of causality, between these variables. Finally, while the most obvious strength of the sample is that it was recruited via sites providing Internet gambling services and furnishes information about individuals who actually use these services, this is also a key limitation. By design, and for reasons of feasibility, the survey involved a self-selected sample, and consequently absolute rates of problematic gambling are an inflated $20.5 \%$, compared with typical general population prevalence estimates of 3.0\% (Kessler et al. 2008; Wardle et al. 2007). While the absolute rates of problem gambling and co-occurring disorders cannot necessarily be generalised directly to the wider population, the figure of $20.5 \%$ is in line with recent studies of other Internet gambling samples (McBride and Derevensky 2009; Wood and Williams 2007), and the broader patterns of gambling behaviours and comorbidities are nonetheless relevant to understanding the health experiences of Internet gamblers specifically. Furthermore, while we can look to general population surveys for reliable prevalence estimates, population surveys typically fail to recruit sufficient numbers of Internet gamblers to allow analyses as detailed as ours. Therefore, we believe the strengths and weaknesses of our study are opposite and complementary to large randomised population surveys.

Internet Gambling, Demographics and Health Experiences In our sample, the largest proportion of respondents were Internet users who were non-tominimal gamblers and lottery players, who spent the least amount of time gambling online, and contained the smallest proportions of problem gamblers. Lottery play is a prominent form of Internet gambling (Wardle et al. 2007), and the relatively low proportion of problem gambling cases is consistent with findings amongst offline lottery players (Kessler et al. 2008). The non-to-minimal gamblers and lottery players 
also reported less alcohol misuse and, together with the sports bettors, were less likely than the casino \& sports gamblers and multi-activity gamblers to score above threshold for previous mood elevation and substance abuse. These findings complement betting patterns suggesting that the modal involvement in Internet gambling is relatively light (LaBrie et al. 2007, 2008), and provide evidence of comparatively low levels of psychopathology in such users. The one discordant observation is the elevated recent use of antidepressants in the lottery players; however, this is most likely attributable to the higher proportions of female respondents within this cluster compared with the other clusters. By contrast, the sports bettors in our sample were the most likely to be educated to degree level or above, most likely to be male, and had been gambling, on average, for longer than any of the other clusters. There were fewer likely problem gamblers amongst them than amongst the casino \& sports bettors, and they were the least likely of all of the clusters to take most recreational drugs, to have symptoms of depression or panic, or to have self harmed for non-gambling-related reasons. At the other end of the behavioural spectrum, the multi-activity gamblers were the most likely to reach 'caseness' for problem gambling, consistent with findings that problem gamblers often engage in multiple forms of gambling (Kessler et al. 2008; LaPlante et al. 2009), and to have parents who gambled, often problematically. The multi-activity gamblers were also the most likely to exhibit features of mood and substance use disorders and to report deliberate self harm, both related and unrelated to their gambling behaviour which also accords with an elevated suicide risk in problem gamblers (Hodgins et al. 2006; Kessler et al. 2008). Over $75 \%$ of individuals in this cluster were male, and their most common educational category was lower than that of all other clusters. They were the least likely to be in a relationship and most likely to be unemployed, 
with below-average selfreported income. The multi-activity gamblers formed only $1.5 \%$ of respondents, but were clearly the most likely to require help for gambling problems: our findings suggest that potential interventions for this group will need to take account of significant psychiatric co-morbidity and social marginalisation rather than simply addressing gambling involvement. This is consistent with conclusions from studies of non-Internet gamblers (Petry et al. 2005). The casino \& sports gamblers constituted $15 \%$ of the total sample, and were the next most likely group to reach threshold for likely problem gambling, and to have engaged in deliberate self harm as a result of their gambling behaviour. In general, the casino \& sports gamblers showed trends weaker, but in a similar direction to the multi-activity gamblers, to have parents who gambled (problematically), to reach 'caseness' for substance abuse, to have taken major illicit and psychotropic drugs within the last 12 months, and to have sought help for addiction. However, the casino \& sports gamblers were demographically quite different, being one of the most likely clusters to be employed and of above average income. These may be important protective factors acting to counteract the potential negative effects of psychological reinforcers of problematic gambling. Sports bettors were similar, demographically, to the casino \& sports bettors, and had similar, intermediate, proportions of alcohol problems but lower use of drugs, and lower rates of psychological comorbidity. An entirely novel feature of this study is the finding of important associations between previous hypomanic experience and Internet gambling, concordant with clinical evidence that suggests an association between bipolar disorders and pathological gambling (McIntyre et al. 2007). While severe forms of bipolar disorder affect only about $1 \%$ of the population, bipolar diagnoses (I, II and NOS) are made in up to $4.4 \%$ of the general population (Merikangas et al. 2007), and hypomanic symptoms are detected in many individuals 
who complain only of depressed mood (Cassano et al. 2004). The MDQ allows a more dimensional approach to measuring hypomanic symptoms, and 'high scorers' are much more likely to experience bipolar mood disturbance and meet formal criteria for a bipolar diagnosis (Chandler et al. 2008). Our findings suggest that bipolar psychopathology (as seen in our MDQ high scorers) may contribute, with its recognised comorbidity of substance misuse, to the risks of Internet problem gambling. Several authors have already suggested that the Internet represents an effective conduit for the pursuit of behaviours that can develop into compulsions or behavioural addictions (Block 2008). Its use is largely anonymous, its services are available $24 \mathrm{~h}$ a day, and the interactive character of its software can be highly engaging. In this context, hypomanic experiences involving sleeplessness, impulsivity and a preoccupation with rewarding activities may promote the development of compulsive Internet behaviours including problematic gambling. Therefore, our data suggest that individuals with hypomania, and other features of bipolar illness, may be at heightened risk for problematic gambling online and other Internet compulsions. This is particularly important given current concerns about increasing compulsive Internet use (Block 2008) and, perhaps, highlights the need for educational interventions about the risks of Internet gambling (and other online services) in individuals with a history of mood elevation. The potential importance for treatment implementation of recognising the heterogeneity of gambling behaviour has already been highlighted in the field of offline gambling (Toneatto and Millar 2004). Our findings demonstrate that this applies powerfully also in the field of Internet gambling. These findings can guide policy makers, who are currently under pressure to implement harm prevention measures in the midst of the substantial growth of the Internet gambling. They may also help identify candidates for online interventions for 
problematic gambling, with recent preliminary studies showing encouraging results (Wood and Griffiths 2007a).

\section{REFERENCES}

American Psychiatric Association. (2000). In A. P. Association (Ed.), Diagnostic and statistical manual of mental disorders. Washington, DC: American Psychiatric Publishing Inc.

Block, J. J. (2008). Issues for DSM-V: Internet addiction. American Journal of Psychiatry, 165, 306-307.

British Medical Association. (2007). Gambling addiction and its treatment within the NHS. A guide for healthcare professionals. London: British Medical Association.

Cassano, G. B., Rucci, P., Frank, E., Fagiolini, A., Dell’Osso, L., Shear, M. K., et al. (2004). The mood spectrum in unipolar and bipolar disorder: Arguments for a unitary approach. American Journal of Psychiatry, 161, 1264-1269.

Chandler, R. A., Wang, P. W., Ketter, T. A., \& Goodwin, G. M. (2008). A new USUK diagnostic project: Mood elevation and depression in first-year undergraduates at Oxford and Stanford universities. Acta Psychiatrica Scandinavica, 118, 81-85.

Clarke, R., \& Dempsey, G. (2001). The feasibility of regulating gambling on the Internet. Managerial and Decision Economics, 22, 125-132.

Ewing, J. A. (1984). Detecting alcoholism: The CAGE questionnaire. Journal of the American Medical Association, 252, 1905-1907.

Goldberg, D. P., Gater, R., Sartorius, N., Ustun, T. B., Piccinelli, M., Gureje, O., et al. (1997). The validity of two versions of the GHQ in the WHO study of mental illness in general health care. Psychological Medicine, 27, 191-197. 
Griffiths, M. (1993). Fruit machine gambling: The importance of structural characteristics. Journal of Gambling Studies, 9, 101-120.

Griffiths, M. (2004). Betting your life on it. BMJ, 329, 1055-1056.

Griffiths, M., \& Barnes, A. (2007). Internet gambling: An online empirical study among student gamblers. International Journal of Mental Health and Addiction, 6, $194-204$.

Griffiths, M., Parke, A., Wood, R., \& Parke, J. (2006). Internet gambling: An overview of psychosocial impacts. UNLV Gaming Research \& Review Journal, 10, 13.

Griffiths, M., Wardle, H., Orford, J., Sproston, K., \& Erens, B. (2009).

Sociodemographic correlates of Internet gambling: Findings from the 2007 British Gambling Prevalence Survey. Cyberpsychology \& Behavior, 12, 199-202.

Hirschfeld, R. M., Williams, J. B., Spitzer, R. L., Calabrese, J. R., Flynn, L., Keck, P. E., Jr., et al. (2000). Development and validation of a screening instrument for bipolar spectrum disorder: The mood disorder questionnaire. American Journal of Psychiatry, 157, 1873-1875.

Hodgins, D. C., Mansley, C., \& Thygesen, K. (2006). Risk factors for suicide ideation and attempts among pathological gamblers. American Journal on Addictions, 15, $303-310$.

Kessler, R. C., Hwang, I., LaBrie, R., Petukhova, M., Sampson, N. A., Winters, K. C., et al. (2008). DSM-IV pathological gambling in the National Comorbidity Survey replication. Psychological Medicine, 38, 1351-1360.

LaBrie, R. A., Kaplan, S. A., Laplante, D. A., Nelson, S. E., \& Shaffer, H. J. (2008). Inside the virtual casino: A prospective longitudinal study of actual Internet casino gambling. European Journal of Public Health, 18, 410-416. 
LaBrie, R., LaPlante, D., Nelson, S., Schumann, A., \& Shaffer, H. (2007). Assessing the playing field: A prospective longitudinal study of Internet sports gambling behavior. Journal of Gambling Studies, 23, 347-362.

Ladd, G. T., \& Petry, N. M. (2002). Disordered gambling among university-based medical and dental patients: A focus on Internet gambling. Psychology of Addictive Behaviors, 16, 76-79.

Ladouceur, R., Boisvert, J. M., Pe 'pin, M., Loranger, M., \& Sylvain, C. (1994). Social cost of pathological gambling. Journal of Gambling Studies, 10, 399-409. LaPlante, D. A., Nelson, S. E., LaBrie, R. A., \& Shaffer, H. J. (2009). Disordered gambling, type of gambling and gambling involvement in the British Gambling Prevalence Survey 2007. European Journal of Public Health, 1-6.

McBride, J., \& Derevensky, J. L. (2009). Internet gambling behavior in a sample of online gamblers. International Journal of Mental Health \& Addiction, 7, 149-167. McIntyre, R. S., McElroy, S. L., Konarski, J. Z., Soczynska, J. K., Wilkins, K., \& Kennedy, S. H. (2007). Problem gambling in bipolar disorder: Results from the Canadian Community Health Survey. Biological Psychiatry, 61, 223s-224s. Merikangas, K. R., Akiskal, H. S., Angst, J., Greenberg, P. E., Hirschfeld, R. M., Petukhova, M., et al. (2007). Lifetime and 12-month prevalence of bipolar spectrum disorder in the National Comorbidity Survey replication. Archives of General Psychiatry, 64, 543-552.

Nower, L., Derevensky, J. L., \& Gupta, R. (2004). The relationship of impulsivity, sensation seeking, coping, and substance use in youth gamblers. Psychology of Addictive Behaviors, 18, 49-55.

Petry, N. M. (2003). A comparison of treatment-seeking pathological gamblers based on preferred gambling activity. Addiction, 98, 645-655. 
Petry, N. M., Stinson, F. S., \& Grant, B. F. (2005). Comorbidity of DSM-IV pathological gambling and other psychiatric disorders: Results from the national epidemiologic survey on alcohol and related conditions. Journal of Clinical Psychiatry, 66, 564-574.

Petry, N. M., \& Weinstock, J. (2007). Internet gambling is common in college students and associated with poor mental health. American Journal on Addictions, 16, $325-330$.

Shaw, M. C., Forbush, K. T., Schlinder, J., Rosenman, E., \& Black, D. W. (2007). The effect of pathological gambling on families, marriages, and children. CNS Spectrums, 12, 615-622.

Siegel, S. (1956). Nonparametric statistics for the behavioral sciences. New York: McGraw Hill.

Skinner, H. A. (1982). The drug abuse screening test. Addictive Behaviors, 7, 363371.

Spitzer, R. L., Williams, J. B., Kroenke, K., Linzer, M., deGruy, F. V., 3rd, Hahn, S. R., et al. (1994). Utility of a new procedure for diagnosing mental disorders in primary care. The PRIME-MD 1000 study. JAMA, 272, 1749-1756.

Stucki, S., \& Rihs-Middel, M. (2007). Prevalence of adult problem and pathological gambling between 2000 and 2005: An update. Journal of Gambling Studies, 23, 245 257.

Toneatto, T., \& Millar, G. (2004). Assessing and treating problem gambling:

Empirical status and promising trends. Canadian Journal of Psychiatry, 49, 517-525. Vermunt, J. K., \& Magidson, J. (2003). Latent gold 3.0 user's guide. Belmont, MA: Statistical Innovations Inc. 
Wardle, H., Sproston, K., Orford, J., Erens, B., Griffiths, M., Constantine, R., \& Piggott, S. (2007). In T. G. Commission (Ed.) British Gambling Prevalence Survey 2007. London: National Centre for Social Research.

Welte, J. W., Barnes, G. M., Wieczorek, W. F., Tidwell, M.-C. O., \& Hoffman, J. H. (2007). Type of gambling and availability as risk factors for problem gambling: A tobit regression analysis by age and gender. International Gambling Studies, 7, 183198.

Wood, R. T. A., \& Griffiths, M. D. (2007a). Online guidance, advice, and support for problem gamblers and concerned relatives and friends: An evaluation of the GamAid pilot service. British Journal of Guidance \& Counselling, 35, 373-389.

Wood, R. T. A., \& Griffiths, M. D. (2007b). Online data collection from gamblers: Methodological issues. International Journal of Mental Health Addiction, 5, 13. Wood, R. T., Griffiths, M. D., \& Parke, J. (2007). Acquisition, development, and maintenance of online poker playing in a student sample. Cyberpsychology and Behavior, 10, 354-361.

Wood, R. T., \& Williams, R. J. (2007). Problem gambling on the Internet: Implications for Internet gambling policy in North America. New Media \& Society, 9, $520-542$.

Wood, R. T., \& Williams, R. J. (2009). Internet gambling: Prevalence, patterns, problems, and policy options. Final report prepared for the Ontario Problem Gambling Research Centre, Guelph, Ontario 
Table 1. Demographic characteristics (percentages (N), means and standard deviations) for members of the 5 clusters identified in a latent class analysis (LCA) of 4,125 respondents who completed a web based survey of Internet gambling behaviour.

\begin{tabular}{|c|c|c|c|c|c|c|c|c|c|c|c|c|c|c|c|c|c|c|c|c|}
\hline \multirow[b]{3}{*}{ Whole sample } & \multicolumn{2}{|c|}{$\begin{array}{c}\text { Proportion of } \\
\text { sample }\end{array}$} & \multicolumn{2}{|c|}{ Age } & \multicolumn{2}{|c|}{ Males } & \multicolumn{2}{|c|}{$\begin{array}{l}\text { Married / living } \\
\text { with partner }\end{array}$} & \multicolumn{2}{|c|}{ Have children } & \multicolumn{2}{|c|}{$\begin{array}{c}\text { Educated to } \\
\text { degree level + }\end{array}$} & \multicolumn{2}{|c|}{ Employed } & \multicolumn{2}{|c|}{ Students } & \multicolumn{2}{|c|}{$\begin{array}{l}\text { Below average } \\
\text { income }\end{array}$} & \multicolumn{2}{|c|}{$\begin{array}{c}\text { Above average } \\
\text { income }\end{array}$} \\
\hline & $\%$ & $\mathrm{~N}$ & Mean & SD & $\%$ & $\mathrm{~N}$ & $\%$ & $\mathrm{~N}$ & $\%$ & $\mathrm{~N}$ & $\%$ & $\mathrm{~N}$ & $\%$ & $\mathrm{~N}$ & $\%$ & $\mathrm{~N}$ & $\%$ & $\mathrm{~N}$ & $\%$ & $\mathrm{~N}$ \\
\hline & 100 & 4125 & 35.53 & 11.76 & 79.1 & 3263 & 52.8 & 2178 & 34.7 & 1431 & 41.8 & 1724 & 73.4 & 3028 & 10.6 & 437 & 29.0 & 1196 & 35.5 & 1464 \\
\hline $\begin{array}{l}\text { Cluster 1: Non-to- } \\
\text { minimal gamblers }\end{array}$ & 39.6 & 1619 & 36.32 & 12.27 & 65.7 & 1064 & 55.5 & 899 & 38.3 & 620 & 41.0 & 664 & 67.7 & 1096 & 11.2 & 181 & 32.9 & 533 & 30.6 & 495 \\
\hline $\begin{array}{l}\text { Cluster 2: Sports } \\
\text { bettors }\end{array}$ & 34.7 & 1418 & 35.63 & 11.53 & 95.8 & 1358 & 51.0 & 723 & 29.7 & 421 & 46.9 & 703 & 79.0 & 1120 & 10.1 & 143 & $23.8 \%$ & 337 & 42.9 & 608 \\
\hline $\begin{array}{l}\text { Cluster 3: Casino \& } \\
\text { sports bettors }\end{array}$ & 15.0 & 614 & 32.03 & 10.14 & 91.8 & 564 & 44.9 & 276 & 30.7 & 188 & 37.6 & 231 & 76.6 & 470 & 12.2 & 75 & 27.2 & 167 & 37.8 & 232 \\
\hline $\begin{array}{l}\text { Cluster 4: Lottery } \\
\text { players }\end{array}$ & 9.3 & 379 & 37.91 & 10.94 & 53.8 & 204 & 64.1 & 233 & 42.0 & 159 & 35.1 & 133 & 74.4 & 282 & 6.6 & 25 & 32.0 & 121 & 28.5 & 108 \\
\hline $\begin{array}{l}\text { Cluster 5: Multi- } \\
\text { activity gamblers }\end{array}$ & 1.5 & 60 & 33.05 & 15.21 & 77.6 & 47 & 36.2 & 22 & 55.0 & 30 & 30.0 & 18 & 56.6 & 34 & 13.3 & 8 & 46.7 & 28 & 16.7 & 10 \\
\hline
\end{tabular}


Table 2. 'Caseness' across LCA clusters (Cluster $5 \%$ s are included in analysis but omitted from figures as they are derived from only 60 cases).

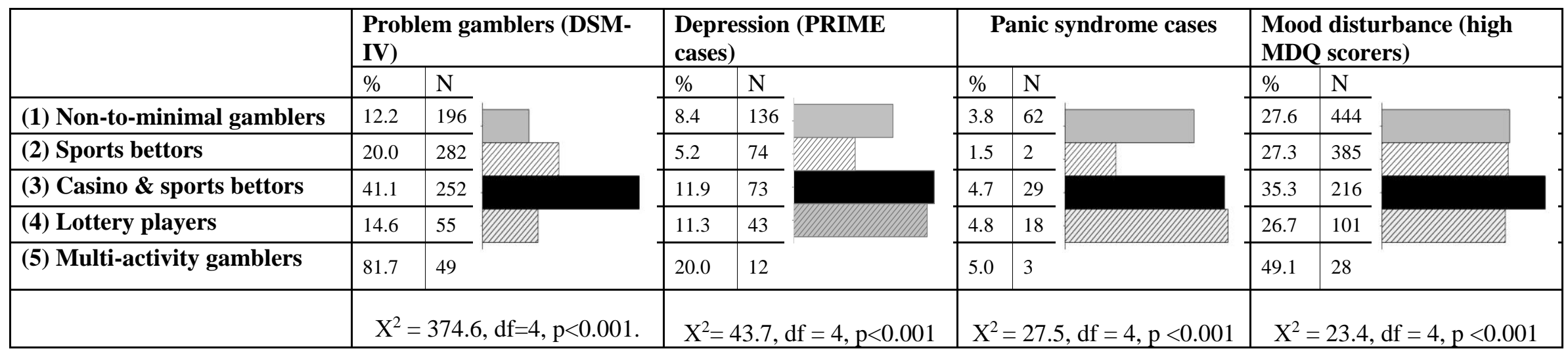

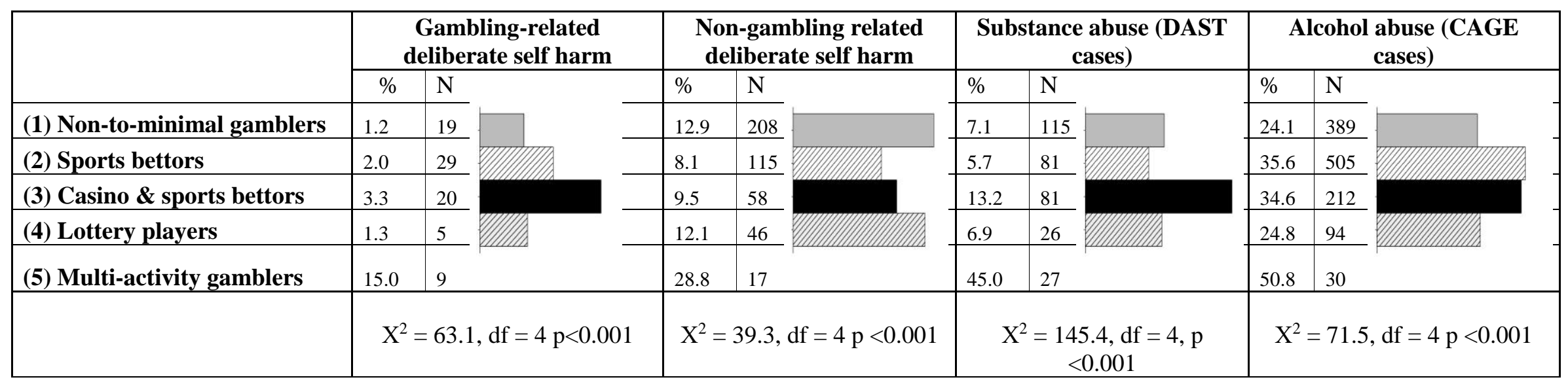


Table 3. Drug use across LCA clusters (Cluster $5 \%$ s are included in analysis but omitted from figures as they are derived from only 60 cases).

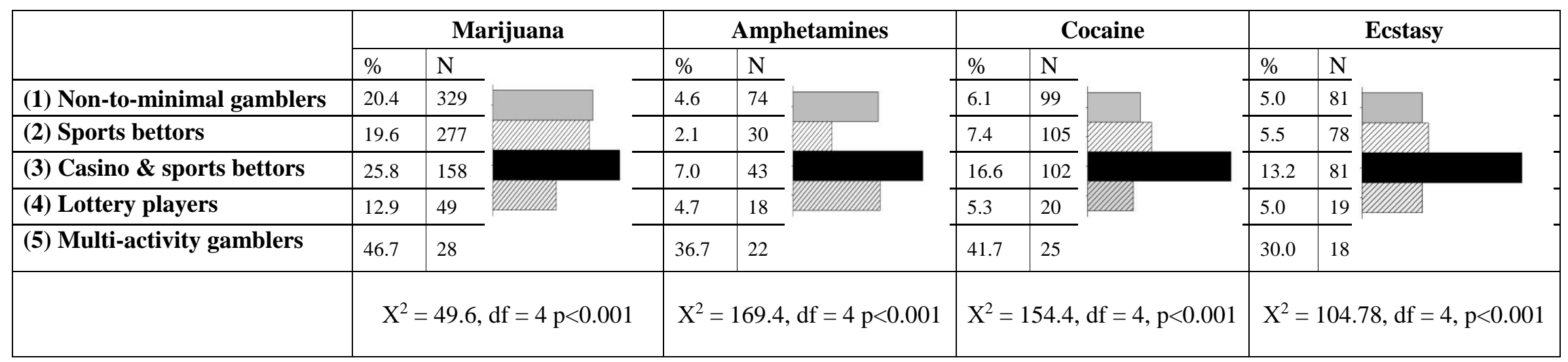

\begin{tabular}{|c|c|c|c|c|c|c|c|c|}
\hline & \multicolumn{2}{|r|}{ Heroin } & \multicolumn{2}{|r|}{ Benzodiazepines } & \multicolumn{2}{|r|}{$\begin{array}{c}\text { Prescribed } \\
\text { antidepressants }\end{array}$} & \multicolumn{2}{|r|}{ Nicotine } \\
\hline & $\%$ & $\mathrm{~N}$ & $\%$ & $\mathrm{~N}$ & $\%$ & $\mathrm{~N}$ & $\%$ & $\mathrm{~N}$ \\
\hline (1) Non-to-minimal gamblers & 0.7 & 12 & 4.8 & 78 & 12.0 & 194 & 40.3 & 651 \\
\hline (2) Sports bettors & 0.3 & 4 & 2.6 & 37 & 4.8 & 68 & 35.7 & 505 \\
\hline (3) Casino \& sports bettors & 2.6 & 16 & 7.2 & 44 & 9.3 & 57 & 43.4 & 266 \\
\hline (4) Lottery players & 0.5 & 2 & 4.5 & 17 & 17.8 & 67 & 40.1 & 152 \\
\hline \multirow[t]{2}{*}{ (5) Multi-activity gamblers } & 30.0 & 18 & 27.1 & 16 & 33.9 & 20 & 58.3 & 35 \\
\hline & \multicolumn{2}{|c|}{$X^{2}=419.0, d f=4, p<0.001$} & \multicolumn{2}{|c|}{$\mathrm{X}^{2}=88.4, \mathrm{df}=4, \mathrm{p}<0.001$} & \multicolumn{2}{|c|}{$\mathrm{X}^{2}=113.3, \mathrm{df}=4, \mathrm{p}<0.001$} & \multicolumn{2}{|c|}{$\mathrm{X}^{2}=22.0, \mathrm{df}=4, \mathrm{p}<0.001$} \\
\hline
\end{tabular}




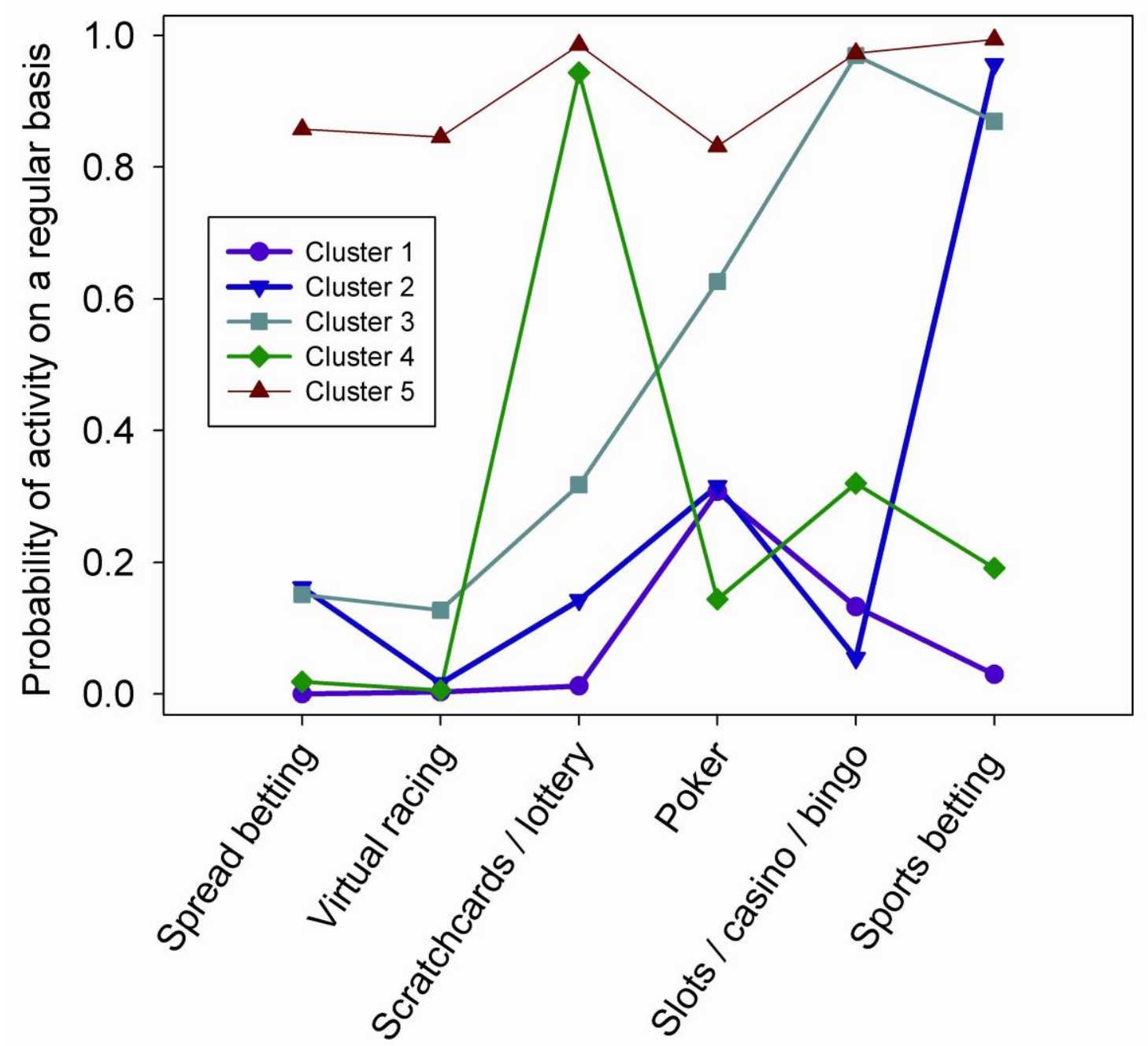


Fig. 1 Optimal latent class solution (probabilities that members of each cluster engage in each category of Internet gambling) 